\title{
Time-dependent Changes in Concentration of Two Clinically Used Acetylcholinesterase Reactivators (HI-6 and Obidoxime) in Rat Plasma Determined by HPLC Techniques after in vivo Administration
}

\author{
Jana Zdarova Karasova, ${ }^{* 1 \dagger}$ Ladislav Novotny, ${ }^{* 2}$ Karel ANTOS, ${ }^{* 3}$ Helena ZivnA, ${ }^{* 4}$ and \\ Kamil KUCA $* 2, * 5$ \\ *1 Department of Toxicology, Faculty of Health Sciences, University of Defence, Trebesska 1575, \\ 50001 Hradec Kralove, Czech Republic \\ *2 Center of Advances Studies, Faculty of Health Sciences, University of Defence, Trebesska 1575, \\ 50001 Hradec Kralove, Czech Republic \\ *3 Department of Public Health, Faculty of Health Sciences, University of Defence, Trebesska 1575, \\ 50001 Hradec Kralove, Czech Republic \\ *4 Radioisotope Laboratories and Vivarium, Faculty of Medicine, Charles University, Simkova 870, \\ 50038 Hradec Kralove, Czech Republic \\ *5 Department of Chemistry, Faculty of Sciences, J. E. Purkinje University, Horeni 13, 40096 Usti nad Labem, \\ Czech Republic
}

\begin{abstract}
A simple and reliable HPLC method for determination of rat plasma levels of clinically used acetylcholinesterase (AChE) reactivators (HI-6 and obidoxime) is presented in our study. Separation was carried out by HPLC using an octadecyl silica stationary phase and a mobile phase consisting of $24 \%$ acetonitrile and containing $5 \mathrm{mM}$ sodium octanesulfonate and $5 \mathrm{mM}$ tetramethylammonium chloride $(\mathrm{pH} 2.3)$. Following intramuscular administration of equimolar doses of both oximes $(22.23 \mathrm{mg} / \mathrm{kg})$, the maximum of HI-6 concentration in rat plasma was reached in about 20 min giving $15.26 \pm$ $1.71 \mu \mathrm{g} / \mathrm{mL}$. The distribution of obidoxime was fast; the single maximum $23.62 \pm 3.563 \mu \mathrm{g} / \mathrm{mL}$ was recorded at about $10 \mathrm{~min}$. HPLC with UV detection presented in our study is a general method which could be applied for quick measurements of bisquaternary AChE reactivators in rat plasma.
\end{abstract}

(Received August 20, 2009; Accepted October 20, 2009; Published January 10, 2010)

\section{Introduction}

Organophosphates (OPs) are widely used all over the world as pesticides (insecticides, acaricides). Some chemicals similar to these compounds are used in the chemical industry as softeners or additives to lubricants. ${ }^{1}$ The most toxic OPs are called "nerve agents" (tabun, sarin, soman, cyclosarin, VX and Russian VX). They could be misused by terrorist groups or as warfare agents. ${ }^{2,3}$ The main mechanism of action of OPs is based on irreversible inhibition of cholinesterases (especially acetylcholinesterase, AChE; EC 3.1.1.7) via a covalent reaction with the serine in the active center of the enzyme. ${ }^{4}$ Blocked AChE causes accumulation of neurotransmitter acetylcholine at the vicinity of nerve terminals with subsequent overstimulation of cholinergic receptors of the central and peripheral nervous system. ${ }^{5-7}$

AChE reactivators (oximes) that act by breaking the bond between AChE and OPs, thus freeing AChE. The action of oximes occurs most markedly at nicotinic sites (neuromuscular junctions). Pralidoxime (mono-pyridinium oxime) was the first

† To whom correspondence should be addressed.

E-mail: karasova@pmfhk.cz effective reactivator used for treatment of human organophosphate intoxication. ${ }^{8}$ Other important oximes for antidotal treatment that may be clinically used are obidoxime (Toxogonin ${ }^{\circledR}$, Pirrangit $^{\circledR}$, Toxobindin ${ }^{\circledR}$ ) and HI- $6 .{ }^{9}$

Animal data derived from rats exposed to OPs consistently shows a marked positive effect of these compounds on survival; HI-6 has been shown to cause low acute toxicity. This reactivator is one of the most promising commonly used reactivators with a broad spectrum of efficacies and is also far superior to the established pralidoxime. ${ }^{10,11}$ Obidoxime is sufficiently effective against tabun and pesticides. ${ }^{12-14}$

Chemically, HI-6 is an asymmetric bis-pyridinium monoaldoxime (1-(2-hydroxyiminomethylpyridinium)-3-(4carbamoylpyridinium)-2-oxapropane dichloride). The molecular weight without anion is 288.30. Obidoxime is a symmetric bis-pyridinium dialdoxime (1,3-bis(4-hydroxyiminomethylpyridinium)-2-oxapropane dichloride) with a molecular weight without anion of 288.30. The linkers connecting pyridinium rings AChE reactivators are identical, 2-oxapropane. The structures are shown in Fig. 1.

The distribution study of oximes is important because it will aid evaluation of oximes as rapid antidotes for OPs poisoning. This basic distribution knowledge is also important for safe use 


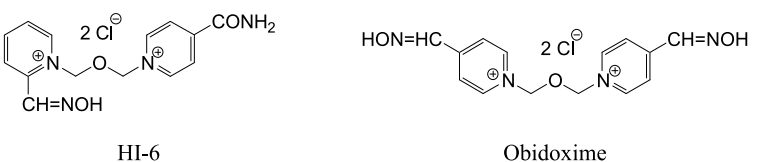

Fig. 1 Structures of tested oximes.

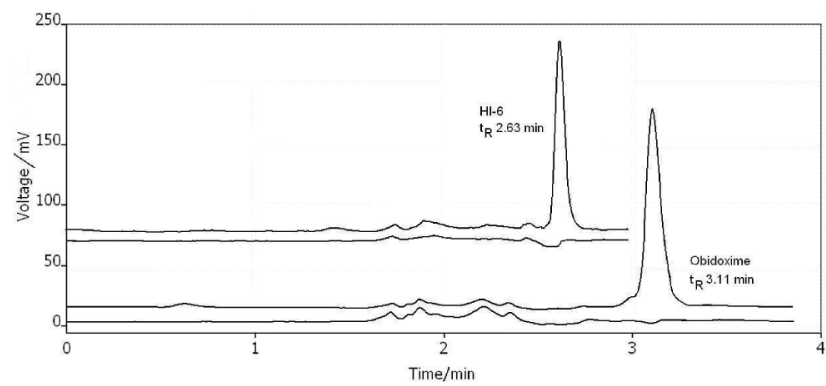

Fig. 2 HPLC chromatogram of rat plasma sample.

of these oximes in clinical practice and for prevention of overdoses of oximes during treatment of OPs casualties.

Several methods have been reported for quantitative determination of $\mathrm{AChE}$ reactivators in pharmaceutical preparations ${ }^{15,16}$ and in biological samples. ${ }^{17,18}$ The most suitable determination which may be used for measuring plasma concentrations is high-performance liquid chromatography (HPLC) with UV detection. However, in the HPLC method reported by Houze et al. ${ }^{19}$ of applying electrochemical detection for measurement of mono-pyridinium oxime (pralidoxime) concentration in human serum, a 10 -fold increase in sensitivity could be reached. The level of oxime concentration in plasma is relatively high and, due to the detection limit of UV detector (around $500 \mathrm{ng} / \mathrm{mL}$ ), is suitable for this analytical approach. ${ }^{17}$ The HPLC method of applying electrochemical detection may be used for determination of oximes in brain. In the present study, we report on a simple and sensitive HPLC/UV method suitable to determine HI-6 and also obidoxime with a high precision and sensitivity in rat plasma. This method provides another way to precipitate proteins of the samples. Changes in protein precipitation could also improve methods for determining oxime levels in rat plasma after intramuscular administration.

\section{Experimental}

\section{Reagents and chemicals}

HI-6 and obidoxime were synthesized in our laboratory using general synthetic methods published earlier. ${ }^{20}$ The purity of prepared oximes was approximately $96-99 \%$. Other chemicals were purchased from commercial sources in the analytical grade (Merck, Darmstadt, Germany and Sigma-Aldrich, Steinheim, Germany). The water was double distilled and deionized and of HPLC grade.

\section{Apparatus}

Samples were analyzed by reversed phase HPLC with UV detection. The HPLC system consisted of a P200 gradient pump (Spectra-Physics Analytical, Fremont, USA), a 7125 injection valve, $10 \mu \mathrm{l}$ loop (Rheodyne, Cotati, USA), an UV1000 detector (Spectra-Physics Analytical, USA) and CSW Clarity 2.6.5.517 software (DataApex, Prague, Czech Republic).
Table 1 The intra-day and inter-day precision of oxime HI-6 and obidoxime

\begin{tabular}{|c|c|c|c|}
\hline Concentration & C.V., \% & Mean \pm standard deviation & $n$ \\
\hline \multicolumn{4}{|c|}{ Added $(\mu \mathrm{g} / \mathrm{mL})$ of HI- 6} \\
\hline \multicolumn{4}{|l|}{ Inter-day } \\
\hline 5.0 & 4.06 & $4.9 \pm 0.2$ & 10 \\
\hline 10.0 & 5.21 & $9.8 \pm 0.5$ & 10 \\
\hline 20.0 & 3.92 & $20.8 \pm 0.8$ & 10 \\
\hline 30.0 & 2.76 & $30.1 \pm 0.8$ & 10 \\
\hline 40.0 & 3.03 & $39.2 \pm 1.2$ & 10 \\
\hline \multicolumn{4}{|l|}{ Intra-day } \\
\hline 5.0 & 5.68 & $5.2 \pm 0.3$ & 3 \\
\hline 10.0 & 4.33 & $9.9 \pm 0.4$ & 3 \\
\hline 20.0 & 4.95 & $19.7 \pm 1.0$ & 3 \\
\hline 30.0 & 3.75 & $30.1 \pm 1.1$ & 3 \\
\hline 40.0 & 3.42 & $39.7 \pm 1.4$ & 3 \\
\hline \multicolumn{4}{|c|}{ Added $(\mu \mathrm{g} / \mathrm{mL})$ of obidoxime } \\
\hline \multicolumn{4}{|l|}{ Inter-day } \\
\hline 5.0 & 3.59 & $5.1 \pm 0.2$ & 10 \\
\hline 10.0 & 3.36 & $10.3 \pm 0.4$ & 10 \\
\hline 20.0 & 5.48 & $19.7 \pm 1.01$ & 10 \\
\hline 30.0 & 5.27 & $29.4 \pm 1.6$ & 10 \\
\hline 40.0 & 3.77 & $40.1 \pm 1.5$ & 10 \\
\hline \multicolumn{4}{|l|}{ Intra-day } \\
\hline 5.0 & 7.04 & $4.9 \pm 0.3$ & 3 \\
\hline 10.0 & 3.81 & $10.0 \pm 0.4$ & 3 \\
\hline 20.0 & 5.93 & $20.6 \pm 1.2$ & 3 \\
\hline 30.0 & 3.01 & $30.9 \pm 0.9$ & 3 \\
\hline 40.0 & 6.68 & $39.9 \pm 2.7$ & 3 \\
\hline
\end{tabular}

\section{Methods}

The analytical column used in our study was LiChrospher ${ }^{\circledR}$ $60,250 \times 4.6(5 \mu \mathrm{m})$, with the same type of guard column $4 \times$ 4 (Merck, Germany). The mobile phase was $24 \%$ acetonitrile (gradient grade)/double distilled and deionized water, it contained $5 \mathrm{mmol} / \mathrm{L}$ sodium octanesulfonate and $5 \mathrm{mmol} / \mathrm{L}$ tetramethylammonium chloride. The $\mathrm{pH}$ was adjusted to 2.3 with $\mathrm{H}_{3} \mathrm{PO}_{4}$. The flow rate of the mobile phase was $1 \mathrm{~mL} / \mathrm{min}$ (Fig. 2). The maximum of absorbancy for HI-6 is $310 \mathrm{~nm}$ and for obidoxime it is $296 \mathrm{~nm}$. Both oximes in plasma were measured at wavelengths corresponding with their maximum absorbances. Separation was carried out at $22^{\circ} \mathrm{C}$.

\section{Stability of frozen samples}

HI-6 and also obidoxime samples in plasma in various concentrations $(5,10,20,30$ and $40 \mu \mathrm{g} / \mathrm{mL} ; n=4$, respectively) were stable for at least 3 months when stored at $-80^{\circ} \mathrm{C}$.

\section{Precision}

Intra-day precision was determined by repeating the measurements of spiked plasma samples ten times with five different concentrations $(5,10,20,30$ and $40 \mu \mathrm{g} / \mathrm{mL} ; n=4)$ on the same day. Inter-day precision was determined by calculating the means of four replicates of plasma samples spiked by both oximes $(5,10,20,30$ and $40 \mu \mathrm{g} / \mathrm{mL})$ on three subsequent days. ${ }^{21}$

The intra-day and inter-day coefficients of variations (C.V.) of both oximes are summarized in Table 1 .

\section{Accuracy}

HI-6 in plasma samples $(5,10,20,30$ and $40 \mu \mathrm{g} / \mathrm{mL})$ was quantified once a day on ten different days. The accuracy was 98.2\% $\quad(5 \mu \mathrm{g} / \mathrm{mL}), \quad 98.7 \% \quad(10 \mu \mathrm{g} / \mathrm{mL}), \quad 98.3 \% \quad(20 \mu \mathrm{g} / \mathrm{mL})$, $99.0 \%(30 \mu \mathrm{g} / \mathrm{mL})$ and $98.8(40 \mu \mathrm{g} / \mathrm{mL})$, respectively. 


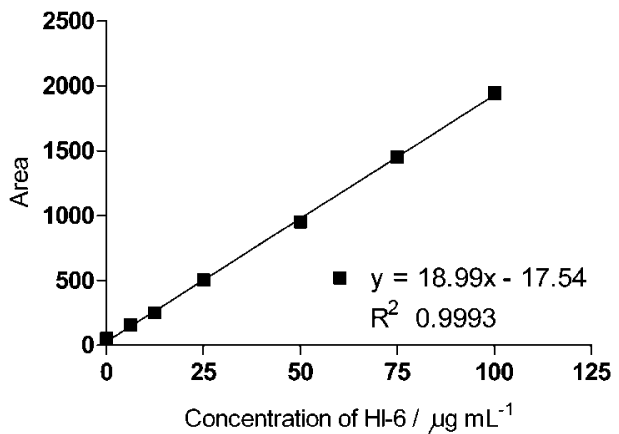

Fig. 3 Calibration plot of rat plasma samples spiked with HI-6.

Obidoxime in plasma samples in the same concentrations was quantified by the same way. The accuracy was $97.9 \%$ $(5 \mu \mathrm{g} / \mathrm{mL}), \quad 98.9 \% \quad(10 \mu \mathrm{g} / \mathrm{mL}), \quad 99.1 \% \quad(20 \mu \mathrm{g} / \mathrm{mL}), \quad 99.0 \%$ $(30 \mu \mathrm{g} / \mathrm{mL})$ and $99.6 \%(40 \mu \mathrm{g} / \mathrm{mL})$.

\section{Limit of quantification $(L O Q)$ and limit of detection ( $L O D)$}

LOQ was calculated as the lowest concentration of samples which could be measured with a precision of $20 \%$ and a relative error of $\pm 20 \%$. The LOD was derived from LOQ according to the equation $\mathrm{LOD}=(3.3 \times \mathrm{LOQ}) / 10$.

The LOQ for oxime HI- 6 was $2.00 \mu \mathrm{mol} / \mathrm{L}$ and the LOD was $0.66 \mu \mathrm{mol} / \mathrm{L}$. The limits of obidoxime were different. The limit of LOQ for obidoxime was $0.80 \mu \mathrm{mol} / \mathrm{L}$ and that of LOD was $0.26 \mu \mathrm{mol} / \mathrm{L}$.

\section{Animal treatment}

Male Wistar rats (Anlab Inc., Prague, Czech Republic) were kept in an animal house regulated for temperature $\left(22 \pm 2^{\circ} \mathrm{C}\right)$, humidity $(55 \pm 6 \%)$, and $12 \mathrm{~h}$ light-dark cycle with light on at $7.00 \mathrm{am}$. Standard laboratory food and tap water were available ad libitum. Housing of animals was provided in the Vivarium of Medical Faculty, Hradec Kralove. The experiment was performed under permission and supervision of the Ethic Committee of the Medical Faculty, Charles University, Hradec Kralove, Czech Republic. ${ }^{22}$

After 7 days of acclimatization, rats (body weight $320 \pm 10 \mathrm{~g}$ SD) were injected intramuscularly (i.m.) with $22.23 \mathrm{mg} / \mathrm{kg}$ of body weight of HI- 6 and obidoxime, equimolar doses close to the therapeutical levels (according to the $5 \%$ of $\mathrm{LD}_{50}$ ). Both oximes were freshly dissolved in physiological saline solution before the applications $(0.1 \mathrm{~mL} / 100 \mathrm{~g}$ of animal weight).

Fourteen animals were used during the experiment; they were divided into two groups. The animals were narcotized by a single dose of pentobarbital (administered intraperitoneally; $50 \mathrm{mg} / \mathrm{kg}$ of body weight) and cannulation of arteria carotis and vena jugularis were performed. Blood was obtained from arteria carotis. The blood loss was replaced by saline solution $(300 \mu \mathrm{L})$ via vena jugularis. The blood samples were withdrawn just before administration of oximes (control time, $0 \mathrm{~min}$ ) and subsequently in time intervals: $3,5,10,20,40,60,90,120$ and $180 \mathrm{~min}$ after application of oximes. All animals survived. Blood $(300 \mu \mathrm{L})$ was gently mixed with heparin $(6 \mu \mathrm{L})$ and plasma was separated by centrifugation $\left(1600 \mathrm{~g}, 10 \mathrm{~min}, 4^{\circ} \mathrm{C}\right.$, Universal 320R, Hettich, Germany). The plasma samples were kept frozen at $-80^{\circ} \mathrm{C}$ until HPLC analysis for one week.

\section{Sample preparation}

The rat plasma samples of $60 \mu \mathrm{L}$ were mixed with $60 \mu \mathrm{L}$ of acetonitrile to precipitate proteins. Then the samples were

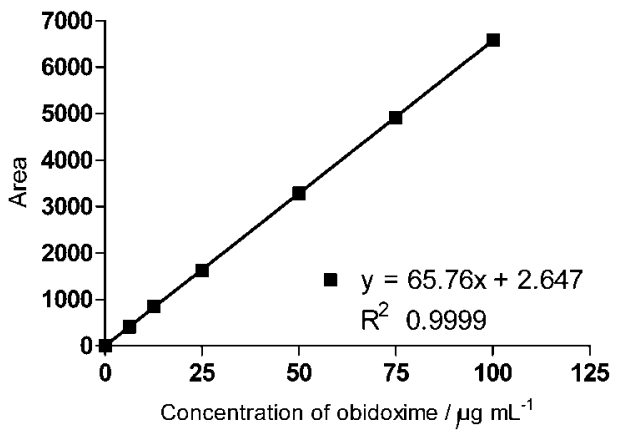

Fig. 4 Calibration plot of rat plasma samples spiked with obidoxime.

centrifuged at $12000 \mathrm{~g}$ for $12 \mathrm{~min}\left(4^{\circ} \mathrm{C}\right)$ in a centrifuge, Model 240R (Hettich, Germany). The obtained supernatant was directly used for HPLC analysis without any further dilution or concentration.

\section{Calibration}

Calibration curves were established using rat plasma samples spiked with HI-6 or obidoxime $(1,6.25,12.5,25,50,75$, $100 \mu \mathrm{g} / \mathrm{mL}$ samples, in triplicates). During the day, the stability of HI-6 and of obidoxime spiked plasma samples were sufficient. The spiked samples were kept at $0^{\circ} \mathrm{C}$ and all concentration values were determined as $100 \pm 5 \%$ of the original samples in $24 \mathrm{~h}$. However, rat plasma samples spiked with oximes and also biological samples were measured directly after precipitation and sample preparation. Endogenous compounds (e.g. proteins, etc.) in the biological samples separated well from HI-6 and also from obidoxime. Peaks migrated with retention times of 2.63 min for HI-6 and 3.11 min for obidoxime.

\section{Results and Discussion}

As shown in Figs. 3 and 4, the calibration curves for both oximes were linear in the range of $1-100 \mu \mathrm{g} / \mathrm{mL}$. Regression analysis performed by the least-squares method yielded the equation $y=18.99 x-17.54$ for HI-6, correlation coefficient of $R^{2}=0.9993$ and the equation $y=65.76 x+2.947$ for obidoxime, correlation coefficient $R^{2}=0.9999$. During the sample preparation, $10 \%$ of oximes were lost. Calibration curves and final concentration determinations were calculated by using Prism4 (Graph Pad Software, USA).

Rat plasma levels of HI-6 and obidoxime were determined in two series of experiments. Following both i.m.oximes injections, a fast rise of blood level was found. HI-6 gave a single maximum around $20 \mathrm{~min}$ and obidoxime gave one around $10 \mathrm{~min}$. After the i.m.treatment, the maximum HI-6 concentration in rat plasma was $15.26 \pm 1.71 \mu \mathrm{g} / \mathrm{mL}$ (Fig. 5). The elimination of HI- 6 after i.m. injected therapeutical dose outweigh at $20 \mathrm{~min}$. The administration of obidoxime also resulted in single maximum of rat plasma concentration around $10 \mathrm{~min}$, it was $23.62 \pm 3.56 \mu \mathrm{g} / \mathrm{mL}$ (Fig. 6). The depression of obidoxime plasma level after i.m.injected therapeutical dose outweigh at $10 \mathrm{~min}$.

Several techniques including HPLC have been reported to measure concentrations of different cholinesterase reactivators in plasma. $^{15-19}$ Cooper(II)-silica ligand exchange chromatography was used for determination of pralidoxime concentration in plasma and urine. ${ }^{18}$ Later on, reversed-phase HPLC on octadecyl silica stationary phase was used for the 


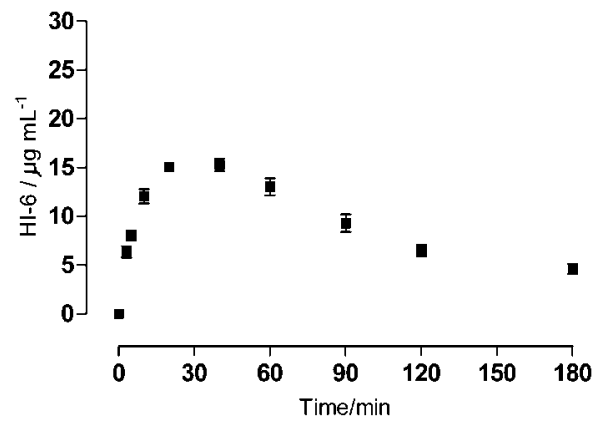

Fig. 5 Rat plasma level of HI-6 following intramuscular administration showed a fast rise; it reached its maximum 15.26 \pm $1.71 \mu \mathrm{g} / \mathrm{mL}$ (SD) at $20 \mathrm{~min}$.

determination of pralidoxime. The previous experiments indicated that changing the organic modifier of the mobile phase has a very limited effect on the chromatographic behavior of this type of solute. Because of the polar origin of oximes, especially bis-pyridinium oximes, their separation was complicated.

Nowadays the levels of oximes are being determined by HPLC analysis on an octyl silica column, with mobile phase including sodium octanesulfonate (OSA) as the ion-pairing reagent. The use of OSA improves the selectivity of the chromatographic system. However, neither the effects of the anorganic modifier concentration nor the ion-pairing agent are also limited. ${ }^{23}$

As a precipitate agent trichloroacetic acid (TCA) is usually used. TCA may disturb chromatographic conditions, especially in ion-pairing chromatography. This was confirmed also in our study. The levels of oximes in samples precipitated by TCA were reduced about $85 \%$, but the retention times of the rest were unchanged. The substantive part of oxime $(\sim 85 \%)$ was eluted at the start of each chromatogram with proteins. Based on these experiences, acetonitrile was used as the precipitate agent (Fig. 7).

In our methodology, the rat plasma levels of both oximes were determined also by using an ion-pairing agent as discussed above. The mobile phase contained a higher range of OSA $(5 \mathrm{mM})$ and was combined with tetramethylammonium chloride (TMA) (also $5 \mathrm{mM}$ ). TMA decreases peak tailing and also works against the OSA and accelerates the passage of oximes. The changes in ratio between OSA and TMA influence the quality of peaks and the retention times of tested oximes (TMA's competitive with oximes about "dividing places" and so speeds the permeability through the column). The other important factor that markedly changes the retention time in this methodology is the $\mathrm{pH}$ of the mobile phase. The lower $\mathrm{pH}$ accelerates passage of oximes because of decrease of the action of OSA and also decreases the ability to influence separation by proteins. The final mobile phase was adjusting for quick measurement of oximes' levels in rat plasma samples. This principle may be used also for separation of two and more oximes in one sample.

After i.m.injection, fast rises of the oxime blood levels were found. Although doses of applied oximes were equimolar, the maximal concentrations in rat plasma were different. The distribution of obidoxime was really fast, and the single maximum $23.62 \pm 3.56 \mu \mathrm{g} / \mathrm{mL}$ was recorded at about $10 \mathrm{~min}$. Maximal rat plasma level of HI-6 was reached at about $20 \mathrm{~min}$ after i.m.application and the value was only $15.26 \pm 1.71 \mu \mathrm{g} / \mathrm{mL}$.

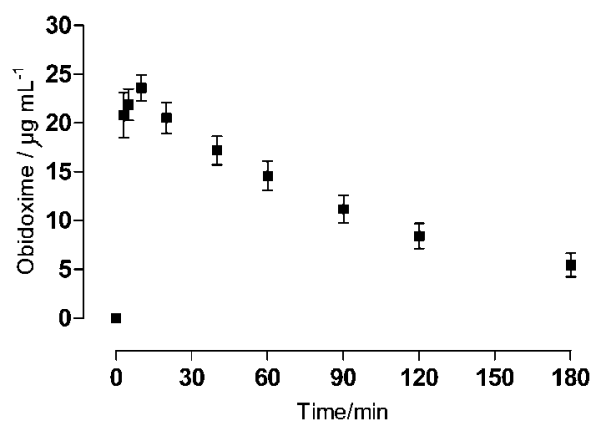

Fig. 6 Rat plasma level of obidoxime following intramuscular administration showed a fast rise; it reached its maximum $23.62 \pm$ $3.56 \mu \mathrm{g} / \mathrm{mL}(\mathrm{SD})$ at $10 \mathrm{~min}$.

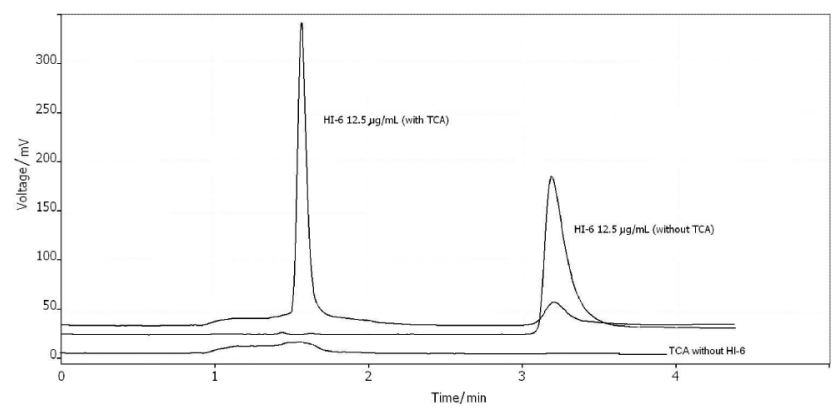

Fig. 7 The precipitation of oxime by TCA.

This is approximately $65 \%$ compared with maximal rat plasma concentration of obidoxime.

Similar distribution curves were found in formerly published studies with structurally close reactivators. ${ }^{23,24}$ The elimination of these compounds was also very fast; $180 \mathrm{~min}$ after i.m. application, the concentration had decreased to $20-15 \%$ compared to maximum (Kalasz, Tekesz). The elimination recorded in our study has similar character, but the reduction of concentration after $180 \mathrm{~min}$ was not so strong. The levels of oximes were around $30 \%$ of maximal concentration. The weak elimination obtained in our study may be explained by lower doses of reactivators (correspond with therapeutical doses), the higher maximal concentration evoked acceleration of cleaning mechanisms. Our choices of therapeutical doses compared to doses chosen by Kalasz et al. and Tekes et al. were caused by the requirement to be very close to the reality.

\section{Conclusion}

This HPLC method with UV detection enabled us to determine changes of reactivator plasma levels. Such a simple quick analytical method could be recommended for monitoring of nerve agent antidotes (e.g. AChE reactivators) in future in vivo studies.

\section{Acknowledgements}

This project was sponsored by the research grant of the Czech Ministry of Defence (No. OVUOFVZ200811). 


\section{References}

1. L. C. Barthoid and J. G. Schier, Crit. Care. Clin., 2005, 21, 673.

2. L. Szinicz, Toxicology, 2005, 214, 167.

3. J. Zdarova Karasova, J. Kassa, Y. S. Jung, K. Musilek, M. Pohanka, and K. Kuca, Int. J. Mol. Sci., 2008, 9, 2243.

4. R. T. Delfino, T. S. Ribeiro, and J. D. Gueroa-Villar, J. Braz. Chem. Soc., 2009, 0, 1.

5. G. Petroianu, L. M. Toomes, A. Petroianu, W. Bergeler, and R. Rüfer, J. Appl. Toxicol., 1998, 18, 293.

6. S. W. Wiener and R. S. Hoffman, J. Intensive Care Med., 2004, 19, 22.

7. J. Zdarova Karasova, J. Bajgar, L. Novotny, and K. Kuca, J. Appl. Biomed., 2009, 7, 93.

8. I. B. Wilson and S. Ginsburg, Biochim. Biophys. Acta, 1955, 18, 169.

9. P. M. Lundy, L. Raveh, and G. Amilai, Toxicol. Rev., 2006, 26, 231.

10. J. Kassa, J. Karasova, K. Musilek, K. Kuca, and J. Bajgar, Clin. Toxicol. (Phila), 2009, 47, 72.

11. J. Kassa, J. Zdarova Karasova, J. Bajgar, S. Tesarova, K. Kuca, and K. Musilek, Basic Clin. Pharmacol. Toxicol., 2009, 104, 228.

12. G. A. Petroianu and D. E. Lorke, Mini-Rev. Med. Chem.,
2008, 3, 1328.

13. D. E. Lorke, S. M. Nurulain, Y. M. Hasan, K. Kuca, K. Musilek, and G. A. Petroianu, Curr. Med. Chem., 2008, 28, 920.

14. J. Z. Karasova, J. Kassa, K. Musilek, M. Pohanka, L. Novotny, and K. Kuca, Int. J. Mol. Sci., 2009, 10, 3065.

15. N. D. Brown, L. L. Hall, H. K. Sleeman, B. P. Doctor, and D. E. Dewaree, J. Chromatogr., 1978, 148, 453.

16. D. Utley, J. Chromatogr., 1987, 396, 237.

17. H. P. Benschop, K. A. Konings, S. P. Kossen, and D. A. Ligtenstein, J. Chromatogr., 1981, 225, 107.

18. F. Guyon, A. Tambute, M. Caude, and R. Rosset, J. Chromatogr., 1982, 229, 475.

19. P. Houze, S. W. Borron, F. Scherninski, B. Bousquet, B. Gourmel, and F. Baud, J. Chromatogr., B, 2005, 814, 149.

20. K. Musilek, L. Lipka, V. Racakova, K. Kuca, D. Jun, V. Dohnal, and M. Dolezal, Chem. Pap., 2006, 60, 48.

21. C. Grasshoff, H. Thiermann, T. Gillessen, T. Zilker, and L. Szinicz, J. Chromatogr., B, 2001, 753, 203.

22. L. Novotny, J. Misik, J. Karasova, K. Kuca, and J. Bajgar, J. Appl. Biomed., 2009, 7, 115.

23. H. Kalasz, Y. M. Hasan, R. Sheen, K. Kuca, G. Petroianu, K. Ludanyi, A. Gergely, and K. Tekes, Anal. Bioanal. Chem., 2006, 385, 1062.

24. K. Tekes, Y. M. Hasan, R. Sheen, K. Kuca, G. Petroianu, K. Ludanyi, and H. Kalasz, J. Chromatogr., A, 2006, 1122, 84. 